\section{Diabetes in Adolescence}

\author{
R. B. Tattersall and J. Lowe \\ Diabetic Department, Nottingham University Hospital, England
}

interest in their own body and need to contemplate the changes in privacy. At home the teenage girl can exclude her brothers and father whereas the diabetic is subjected to frequent physical examinations which, although well intentioned, are seen as an invasion of privacy and modesty. Sexual maturation is also a source of status; the first menstrual period establishes that a girl has "arrived". Penile and muscular growth are similarly important for boys. Long standing childhood diabetes may delay physical and sexual maturation [3] and lead to a sense of inferiority or reinforce previous feelings of being "defective and flawed".

The child develops independence by breaking off long established parental ties while at the same time developing a separate and unique personality. This break may be painful for both child and parents; the child finds it difficult to give up the comfort and security of the home and, to justify his action, may create his own image of parents (and by implication other authority figures including doctors) as dull, old fashioned and lacking in understanding (i. e. something he is justified in rejecting). It is always difficult for parents to relinquish their hold so as to let daugh-

Table 1

\begin{tabular}{ll}
\hline $\begin{array}{l}\text { Aims and problems of "nor- } \\
\text { mal" adolescence }\end{array}$ & How diabetes interferes \\
$\begin{array}{l}\text { 1. Physical and sexual ma- } \\
\text { turation }\end{array}$ & $\begin{array}{l}\text { Delayed sexual maturation } \\
\text { Small stature } \\
\text { "Invasion of privacy" by physical } \\
\text { examinations }\end{array}$ \\
$\begin{array}{l}\text { 2. Independence from } \\
\text { parents and establishment } \\
\text { of a unique personality }\end{array}$ & $\begin{array}{l}\text { May lead to parental over-concern } \\
\text { and battles about diabetes instead } \\
\text { of about }\end{array}$ \\
$\begin{array}{ll}\text { 3. Conformity with the peer } \\
\text { group }\end{array}$ & $\begin{array}{l}\text { Meals have to be eaten on time } \\
\text { "Iunk" foods are forbidden }\end{array}$ \\
$\begin{array}{l}\text { 4. Self consciousness } \\
\text { 5ypoglycaemia exposes the ado- }\end{array}$ \\
$\begin{array}{l}\text { 5. Self esteem } \\
\text { lescent as different } \\
\text { "Economic independence }\end{array}$ & $\begin{array}{l}\text { "Defective" body image } \\
\text { "Loading" of insurance premiums }\end{array}$
\end{tabular}

\section{Normal Adolescence}

The extra difficulties facing the diabetic teenager can only be understood in the context of normal adolescence. The child enters adolescence as a dependent, unthinking, sexually and physically immature being and leaves as a mature and independent adult [2]. The emphasis is on becoming independent and the process is accompanied by dramatic biological and psychological changes (Table 1). Diabetes interferes at every stage as will be seen below.

The growth spurt and sexual maturation require rapid changes of self perception to cope with the changing body image. Normal adolescents feel physically awkward but at the same time have a narcissistic 
ters stay out late or sons go on all day hikes. It is that much more difficult if the child has diabetes. If the girl does not come home on time, is it because she is enjoying herself or might she be unconscious from hypoglycaemia with a boyfriend who has no idea how to cope? When the diabetic boy goes on a hike, similar doubts assail the parents - has he taken glucose tablets? Should I check up or will this be nagging? Friction between teenagers and their parents is more or less normal but the difficulty for the parents of the diabetic is to restrict the conflict to matters such as hair length and fashion rather than allowing it to spill over into rows about urine testing and the management of diabetes.

Even though the adolescent apparently rejects the staid conformity of parents, he himself has a need to conform and be accepted by his peers. Diabetes makes this hard. Friends are, like Huckleberry Finn, free whereas his meals have to be eaten on time, junk foods are forbidden and there is the ever present worry of hypoglycaemia which will expose him as an alien and not all together trustworthy being. $\mathrm{He}$ needs to feel self-important but asks himself how this is possible with the stigma of a defective pancreas. As a child he accepted his illness but now, as he starts to question the meaning of life, he wonders whose fault it is that he has diabetes? Why has he been specially chosen for this inconvenient ailment? What will the future bring?

In the social and economic sphere, the responsibility of work or the anxiety of unemployment loom large. He can expect to be discriminated against by employers merely because he has diabetes [4]. Further examples of the unfairness of the world to the diabetic teenager are not difficult to find.

\section{How Common are Emotional and Psychiatric Problems in Normal and Diabetic Adolescents?}

This brief resume would not lead one to expect that adolescence is always easy, although there is a risk of getting things out of perspective to the extent that adolescence itself becomes a psychiatric disorder. Large surveys of normal teenagers $[5,6]$ show that up to a half have isolated neurotic symptoms and transient feelings of depression.

In the Isle of Wight survey [6] a definable psychiatric disorder was found in only $8 \%$ of "normal" 14-15 year olds, although many more admitted to unexpressed feelings of misery and self-deprecation. Bickering and minor conflicts with parents were common but severe difficulties were conspicuous by their absence. Doubtless surveys in large industrial cities might be less reassuring.
Many investigations of the psychological state of diabetic children and teenagers ignore the background of "normal" adolescence so as to exaggerate the problems of the diabetic. Nevertheless, controlled studies have generally shown that diabetic children and adolescents have more psycho-social problems than their peers. Swift and co-workers [7] compared 50 diabetics aged 7-17 years with 50 matched controls and found increased anxiety, less adequate self-image and more disturbed dependence-independence balance in the diabetics. Similar proportions of the two groups were well adjusted at school but only a quarter of diabetic children compared with two-thirds of the controls were well adjusted at home. Sterky [8] found a similar prevalence of psychiatric disorder in the diabetic and control group but noted that mothers of diabetic children were more depressed and anxious than mothers of controls. Gath and colleagues [9], studying 76 diabetic children (mean age 10.9 years) found a similar prevalence of psychiatric disorder in diabetics and controls but found that a third of families with diabetic children were under stress from pre-existing adverse psycho-social circumstances compared with about a fifth of control families. Without wishing to suggest any aetiological relationships, it is interesting that in one series $77 \%$ of diabetic adolescents had lost a parent before the onset of diabetes compared with $19 \%$ of controls [10]. These are probably chance findings although such deprivation will inevitably make it more difficult for the adolescent to come to terms with his disease.

Sullivan [11] showed that adolescent diabetic girls had significantly more depression and lower selfesteem. Simonds [12] studied 40 well controlled, 40 poorly controlled diabetic children and 40 controls. The number of psychiatric diagnoses were equal in the three groups but it was claimed that the well controlled diabetic group were in the best mental health since they had fewer interpersonal conflicts, fewer non-interpersonal conflicts, less anxiety and depression and families which were less prone to divorce. This should not be taken to imply that good diabetic control improves mental health; it may just be that those teenagers who do what they are told, take care of their diabetes and avoid conflicts!

It is difficult to draw firm conclusions about the mental health of diabetic adolescents in general. It is probably inevitable that teenagers with a chronic disorder will feel some sense of inferiority, but most appear to develop strong defence mechanisms to preserve their personality. Any relative weakness of earlier psychological development will be highlighted by adolescence and patients who have the most trouble with diabetes are usually those who have shown signs 
of personal difficulties before reaching adolescence. It is also certain that the normal turbulence of adolescence will be expressed through upsets in diabetic control. The physician must try to treat normal adolescence problems on their merits and prevent them becoming inextricably intertwined with diabetes and its regulation.

\section{Who Should See the Teenage Diabetic and Where?}

Diabetes is a life-long chronic disorder and continuity of care is important. It has seemed to some that it might be an advantage for the diabetic child to be supervised from the outset by a diabetologist rather than a general paediatrician with a peripheral interest in diabetes. Some paediatricians may be inexperienced in the management of diabetes, out of touch with the latest thinking and will not have their clinical facilities geared to treating diabetics. The advantages of being seen by a paediatrician are that he is used to dealing with children and can evaluate intercurrent conditions better. Furthermore, admission, if necessary, will be to a childrens' rather than an adult ward.

In practice, most children are looked after by a paediatrician until puberty when they transfer to the care of an adult diabetologist. This transfer may be a source of psychological problems; the childrens' clinic is intimate, the patient is made to feel special and often the rules are relatively lax. At worst what will happen to the young diabetic when he transfers to an adult clinic is that he will have a long wait among crowds of elderly patients with white sticks and crutches [13]. When he finally sees the doctor, the interview may be short and he may get the impression that the doctor is not interested in him as a person but only in an incomprehensible concept of "good control".

We believe that children with diabetes should be looked after by a paediatrician but that every attempt should be made to smooth the transition to the adult clinic. We run an adolescent diabetic clinic where the number of patients is restricted and each gets adequate time to get to know the doctor and discuss his problems.

\section{The First Interview}

A disadvantage of the adolescent's developing independence is that he can now stop coming to the clinic if he wishes. Hence, the first interview is critical in that the physician will either establish rapport with his patient or lose him.
The interview should be unhurried and concentrate on getting to know the patient as a person, finding out what he knows about diabetes and what his fears are. It is easy to assume that because someone has had diabetes since childhood he must be "well educated". However tedious it seems, the initial assessment of every patient should include re-education. This is time-consuming but gives both patient and doctor a chance to get to know one another. The doctor's attitude to his teenage patients is important; Stearns [14] has described how the diabetologist can alienate his adult patients. Getting on with teenagers is even more difficult and an authoritarian school masterly approach will usually fail.

At the first visit the diabetologist many well be horrified that his young patient is on a free diet, only one injection a day, and has a haemoglobin $\mathrm{A}_{1}$ of $18 \%$ etc. etc. This first visit is emphatically not the time to make changes, which would be an implicit criticism of previous care and perhaps of the loved and respected paediatrician. Changes in regimen can only be introduced gradually after a relationship has been established and must always be accompanied by full explanation.

\section{Injections}

The adolescent sees life as a frantic rush in which injections are an unwelcome and time-consuming intrusion. The "needle" may also become the focus for the teenagers resentment of diabetes and the restrictions which it imposes. Needle phobia is not usually so much a matter of difficulty with the physical process, but rather an indication of other unresolved psychological problems. Hence, if an adolescent makes unusually vociferous complaints about injections, it is usually better to sit down and talk about it for an hour rather than merely supplying an injection device.

Nevertheless, it is also true that the injection routine is often made needlessly complicated. Glass syringes and spirit are inconvenient and "disposable" plastic syringes are much more suited to the apparently busy life of the adolescent. However, they soon lose their attraction if they have to be disposed of after a single use and paid for out of pocket money or first earnings. The recent demonstration that it is perfectly safe to use such equipment for up to a month without any special sterilisation [15] has been a boon. To simplify the teenage diabetic's life by "bribing" him with a gift of plastic syringes often pays extraordinary dividends in terms of future co-operation and goodwill. 


\section{Diet}

This is the area of management with greatest potential for conflict between parents, physician and teenager. Current dietary practice is frequently illogical and suffers from lack of uniformity [16]. The daily calorie consumption of normal weight individuals taking similar activity varies by up to $100 \%$ [17] and is still greater in adolescence. Is it therefore really logical to put the teenager on a regimented and structured diet? "Junk" foods are the staples of the adolescent subculture; in the USA, for example, $55 \%$ of soft drinks and $20 \%$ of potato crisps are bought by adolescents. An inflexible prohibition of these foods is likely to be disregarded because it overlooks the fact that eating is a form of social intercourse and an expression of friendship and conviviality. The adolescent is likely to reject any regimen which does not compromise by allowing a bottle of cola or a packet of potato crisps as treatment for impending hypoglycaemia. A recent study suggests that precise calorie prescriptions for lean insulin treated patients are not only likely to be disregarded, but are also unnecessary since "auto-regulation" is at least as effective as a calorie defined, exchange type diet [18].

One aspect of diet which concerns all female adolescents is that which relates to their concern with slimming. The non-diabetic girl can easily slim by going onto a crash diet; by contrast, weight reduction in the diabetic girl is often extremely difficult. Reduction in food intake without adequate reduction of insulin dose leads to hypoglycaemia and the food taken to combat this may undo all the previous weight loss and demoralise the patient. If a teenage diabetic is plump, she should be given sensible advice about diet emphasizing that she can lose weight in spite of diabetes and without loss of control.

\section{How Strict Should Control Be and How Should It Be Monitored in the Adolescent?}

The concept of "diabetic control" is ill-understood by most adolescents who think it means not having any symptoms or hospital admissions for ketoacidosis or hypoglycaemia. Getting across the idea that it means "a serious attempt to obtain blood glucose levels as close to those in the non-diabetic as possible" [19] is not easy. One way not to do it is to threaten the patient with future complications if they do not or cannot maintain good control. This is neither fair nor useful because the teenager has enough to cope with without considering his state in 20 years time.

Teenagers dislike testing their urine. Double voiding is a nuisance and Clinitest impossible to use at school or work and an embarrassment when staying at a friend's house. Compliance can be improved by a "dip" method such as Diastix or Testape. However, even these more convenient methods give a poor estimate of blood glucose and many teenagers find adjusting insulin on the basis of such tests misleading and demoralising. They are acutely aware of the possibility of hypoglycaemia and may develop a terror of negative urine tests. To insist that the patient uses tests which he does not trust leads either to non-compliance or faking of the results.

Home blood glucose monitoring has been eagerly accepted by most adolescents [20]. For the "brittle" or problem teenage diabetic, measurement of blood glucose may make all the difference not just in solving problems of control, but in improving motivation and teaching the patient what control means. An unanswered question is how many teenagers will continue to prick their fingers once the novelty has worn off.

Haemoglobin $\mathrm{A}_{1}\left(\mathrm{HbA}_{1}\right)$ is useful for detecting the adolescent whose diabetes in uncontrolled. Some patients will show a marked discrepancy between control measured by $\mathrm{HbA}_{1}$ and urine glucose or blood testing records [21]. The explanation may be a problem with the $\mathrm{HbA}_{1}$ assay but is much more likely to be due to "faking" of tests by the patient because of underlying psychological problems such as a search for perfection or approval, expression of denial or anger, or avoidance of confrontation. Even if one is certain that the patient is not being entirely truthful, it is important not to harass them until they confess. It is much better to explain that there seems to be a problem and offer the teenager some way of saving face, e.g. by reviewing urine testing procedures and giving a chance to reflect and change.

$\mathrm{HbA}_{1}$ has little meaning to the patient and is useless as a means of motivation. It is here that home blood glucose monitoring has its greatest use. When teenagers actually measure blood glucose and discover that theirs is two or three times normal for most of the day, they often relish the challenge of making improvements.

\section{"Brittle" Diabetes - a Multifactorial Problem}

It is often said that the adolescent diabetic is "brittle", a charge which is justified by pointing to the excessive rates of keto-acidosis and hypoglycaemia in the teenage years. We have argued $[22,23]$ that this is usually a passing phase and that after they have reached mature adulthood, these patients will often reveal that the reasons for their apparent uncontrollability were environmental rather than inherent in 
their disease. Often, a brittle state develops because the adolescent leads such an irregular life that he ignores his inconvenient disease and does not stick to any of the rules. Others have never really come to terms with their illness and are determined to prove their normality by not sticking to a diet, etc. Adolescence is a time for experimentation and it is not to be expected that all experiments conducted by the teenage diabetic will have a successful outcome. A single episode of keto-acidosis or hypoglycaemia, which stems from rule breaking should not be regarded as an excuse to chastise the patient.

Sometimes the motivation for being brittle is more deliberately manipulative. Young diabetics may use keto-acidosis as a refuge from unpleasantness at home or school. A survey of children with frequent episodes of keto-acidosis showed that a third came from broken homes or those where the mother was out all day and meals were haphazard [24]. Many freely admitted that they preferred hospital to home. Rosen and Lidz [25] studied 12 patients with two or more episodes of keto-acidosis and considered that in every case the condition had been provoked by deliberate manipulation of diet or insulin. Motives varied from attempted suicide to a wish to seek refuge in hospital. Similar patients have been described many times by others [23, 26]. The critical denominator of the emotionally based brittle adolescent diabetic is that poor control and admissions to hospital serve some underlying psychological need or provide some important secondary gain. This may be attention seeking, an attempt to remain in a dependent state or as the focus for adolescent dependenceindependence conflicts, or as a displacement for some other area of conflict, (e.g. as a form of school avoidance) [27]. Baker and co-workers [28] on the basis of a group of children with an average of 12 admissions per year for diabetic keto-acidosis believe that the tendency to be brittle arises from intrafamilial conflicts. The "sick" diabetic child plays an important part in the family's patterns of conflict avoidance and this role is an important source of reinforcement of symptoms. However, they believe that this brittle state is not due to conscious manipulation but is the result of an exaggerated "turn-on" of catecholamine secretion in response to family conflict and an impaired ability to "turn-off".

Some adolescent problems leading to a brittle state may also be the fault of the doctor. In work done nearly 40 years ago Somogyi [29] suggested that over-treatment with insulin could cause unstable diabetes. It is debatable whether this is due to hormonal counter-regulation or to unsatisfactory insulin regimens [30], but many workers have confirmed that children and adolescents with unstable diabetes are often on excessive doses of insulin [31-33]. We now suspect over-treatment in all patients taking more than 1 unit $\mathrm{kg}^{-1} \mathrm{day}^{-1}$ of insulin and, in general find that dose reduction is possible and leads to improved stability. The biggest problem in the adolescent diabetic clinic is to detect over-treatment in the first instance. It has been well shown that reliance on morning urine or blood tests is no guide to asymptomatic hypoglycaemia during the previous night [34] and inexperienced doctors, faced with a mid-morning blood glucose of $25 \mathrm{mmol} / \mathrm{l}$, are reluctant to believe that the patient does not need more insulin.

\section{Management of Psychological Problems}

Much can be done to prevent or at least live through adolescent diabetic crises. The same doctor should see the patient at each visit since nothing is more discouraging for the teenager than to have to repeat the story of his family traumas over and over again. Time is essential to allow the patient to talk and we always see those with the most difficulties outside clinic hours. An assessment of family dynamics must be done with a home visit by a social worker or diabetes nurse practitioner. The teenager will only develop maturity by facing his problems in the outside world and, especially when it is known that the family situation is the cause of instability, one should make strenous efforts to avoid admissions for "stabilisation". Apart from giving the unwarranted impression that the patient's problems are purely medical, these admissions wreck the continuity of the adolescent's life and make holding down a job impossible.

Patience and the expenditure of time by the diabetologist together with appropriate doses of sympathy and toughness will enable most teenage diabetics to weather their crises. Nevertheless, there will be some occasions when psychiatric help is required. We try to avoid referral unless the patient has a formal psychiatric illness of a depressive or schizophrenic type which needs treating in its own right. Furthermore, splitting the physical and emotional care tends to create confusion and offers unlimited opportunities for manipulation by the patient. We find it useful to discuss our problems with a psychiatrist who can assess the dynamics of the case and formulate them so that the physician can understand more clearly why the patient is reacting as he does and can advise the best methods of dealing with it.

The psychiatrist also provides valuable reassurance that the physician is on the right lines. With the most difficult patients, specialist psychotherapy may be helpful and we have been impressed by the results 
of the family therapy approach used in Philadelphia [35]. Unfortunately, the necessary expertise to embark on family therapy is only available in very few centres.

\section{Miscellaneous Problems}

Sex, alcohol and getting a job loom large in the minds of adolescents, although not necessarily in that order. In Western Europe and the United States, sexual intercourse between adolescents is a fact of life and needs to be discussed. The potential psychological traumas of diabetic adolescence are quite enough without the addition of an unplanned pregnancy which in our experience usually occurs in patients who have the greatest diabetic and psycho-social problems. Unfortunately, not all methods of contraception are suitable for the diabetic adolescent and the best compromise seems to be a progestogenonly pill [36].

Alcohol consumption is a growing part of the adolescent sub-culture in the Western world and, if ordered not to drink, patients will simply refuse to comply. The potential problems need to be discussed in detail with each individual. We usually point out that alcohol is a potent source of calories and will not help weight reduction. Furthermore, it augments the glucose lowering effects of insulin, probably by inhibiting hepatic gluconeogenesis. The further problem which needs to be spelt out in detail is that symptoms of alcohol intoxication and hypoglycaemia are similar and low blood sugar will increase sensitivity to alcohol [37].

Having successfully overcome the pitfalls of school, young diabetics will seek a worthwhile career. Common sense dictates that they should not be employed in jobs where hypoglycaemia might constitute a danger to themselves or others but, unfortunately, there is still much prejudice among employers, especially in times of recession when the diabetic has to compete with "healthy" people. There have been no recent surveys but it is quite possible that the results of Kantrow's study in 1960 [4] are still valid. Fifty three percent of young diabetics had been refused employment, apparently exclusively because of diabetes. Nearly half of those who had not been rejected, always concealed their illness from prospective employers and, not surprisingly, half of those who had experienced rejection subsequently resorted to concealment. We encourage our patients to declare their diabetes at the time of job application, suggesting either that they should use the senior physician as a referee or alternatively getting in touch with a senior executive at the firm to smooth the way.

\section{Conclusions}

The adolescent diabetic has a totally different set of problems from either the child or adult with diabetes. Failure to recognise this and deal with it will result in non-compliance and non-attendance at the clinic. Anyone taking on the care of a teenage diabetic must be prepared to try to resolve all their problems in the one clinic. There is nothing worse for the youngster than to be rendered artificially schizophrenic when she has to attend the dietician for advice on weight reduction, a family planning clinic for advice on contraception, a psychiatrist to find out how to resolve family problems etc. It has been said that when dealing with the interplay between diabetes and psychological factors in the diabetic adolescent, "the well rounded clinician who can treat the disease and the emotional decompensation that accompanies it, is indeed the flower of our profession" [38].

Acknowledgements. We are grateful to Dr. Mark Aveline for valuable advice and discussion.

\section{References}

1. Wickstead JH (1936) The challenge of childhood: An essay on nature and education. Chapman \& Hall, London

2. Wolkind SN, Coleman JC (1976) The psychiatry of adolescence. Br J Hosp Med 16: 572-582

3. Tattersall RB, Pyke DA (1973) Growth in diabetic children. Studies in identical twins. Lancet 2: 1105-1109

4. Kantrow AH (1960) Employment experiences of juvenile diabetics. Diabetes 10: 476-481

5. Henderson AD, Krupinzki J, Stoller A (1972) In: Howells JG (ed) Modern perspectives in modern adolescent psychiatry, vol 4. Brunner Mazel, New York, pp 183-205

6. Rutter M, Graham P, Chadwick OFD, Yule W (1976) Adolescent turmoil: fact or fiction? J Child Psychol Psychiatry 17: $35-56$

7. Swift CR, Seidman F, Stein H (1967) Adjustment problems in juvenile diabetics. Psychosom Med 29: 555-571

8. Sterky G (1963) Family background and state of mental health in a group of diabetic school children. Acta Paediatr Scand 52: $377-390$

9. Gath A, Smith MA, Baum JD (1980) Emotional behavioural and educational disorders in diabetic children. Arch Dis Child 55: $371-375$

10. Stein SP, Charles E (1971) Emotional factors in juvenile diabetics mellitus: a study of early life experiences of adolescent diabetics. Am J Psychiatry 128: 700-704

11. Sullivan BJ (1978) Self-esteem and depression in adolescent diabetic girls. Diabetes Care 1: 18-22

12. Simonds JF (1977) Psychiatric status of diabetic youth matched with a control group. Diabetes 26: 921-925

13. Milner RDG (1978) Diabetes mellitus in adolescence. J R Coll Physicians Lond 12: 240-245

14. Stearns S (1953) Some emotional aspects of the treatment of diabetes mellitus and the role of the physician. N Engl $\mathbf{J}$ Med 249: 471-476

15. Greenhough A, Cockcroft PM, Bloom A (1979) Disposable syringes for insulin injection. Br Med J 2: 1467-1468 
16. Birkbeck JA, Truswell AS, Thomas BJ (1976) Current practice in dietary management of diabetic children: a transatlantic comparison. Arch Dis Child 51: 467-470

17. Hegsted DM (1974) Energy needs and energy utilisation. Nutr Rev 32: 33-38

18. Abraira C, Bartolo M, Mycofski JW (1980) Comparison of unmeasured versus exchange diabetic diets in lean adults: Body weight and feeding patterns in a two year prospective pilot study. Am J Clin Nutr 33: 1064-1070

19. Cahill GF, Etzwiler DD, Freinkel N (1976) Control and diabetes. N Engl J Med 294: 1004-1005

20. Sonksen PH, Judd S, Lowy C (1980) Home monitoring of blood glucose: New approach to management of insulindependent diabetic patients in Great Britain. Diabetes Care 3: 100-107.

21. Citrin W, Ellis GJ, Skler JS (1980) Glycosylated haemoglobin: a tool in identifying psychological problems. Diabetes Care 3 : 563-564

22. Tattersall RB (1977) Brittle diabetes. Clin Endocrinol Metab 6: $403-420$

23. Gale E, Tattersall RB (1979) Brittle diabetes. Br J Hosp Med 22: $589-597$

24. Loughlin WC, Mosenthal HO (1944) Study of the personalities of children with diabetes. Am J Dis Child 68: 13-15

25. Rosen H, Lidz T (1949) Emotional factors in the precipitation of recurrent diabetic keto acidosis. Psychosom Med 11: 211-215

26. Stearns $S$ (1959) Self destructive behaviour in young patients with diabetes mellitus. Diabetes 9: 379-383

27. Greydanus DE, Hofman AD (1979) Psychological factors in diabetes mellitus: A review of the literature with emphasis on adolescence. Am J Dis Child 133: 1061-1066

28. Minuchin S, Baker L, Rosman BL, Liebman R, Milman L, Todd TC (1975) A conceptual model of psychosomatic illness in children. Arch Gen Psychiat 32: 1031-1038
29. Somogyi M (1959) Exacerbation of diabetes by excess insulin action. Am J Med 26: 169-191

30. Gale EAM, Kurtz AB, Tattersall RB (1980) In search of the somogy effect. Lancet 2: 279-282

31. Travis LB (1975) "Overcontrol" of juvenile diabetes mellitus. South Med J 68: 767-771

32. Rosenbloom AL, Giordano BP (1977) Chronic over treatment with insulin in children and adolescents. Am J Dis Child 131: 881-885

33. Gale EAM, Tattersall RB (1979) Unrecognised nocturnal hypoglycaemia in insulin-treated diabetics. Lancet 1: 10491052

34. Winter RJ, Stone NJ, Wise JE, Traisman HS, Green OC (1979) Standard parameters of diabetic control: Are they reliable? Diabetes Care 2: 336-341

35. Minuchin S, Rosman BL, Baker L (1979) Psychosomatic families. Harvard University Press

36. Steel JM, Duncan LJP (1980) Contraception for the insulindependent diabetic woman: the view from one clinic. Diabetes Care 3: 557-560

37. McDonald J (1980) Alcohol and diabetes. Diabetes Care 3: $629-637$

38. Harris HI (1971) The range of psychosomatic disorders in adolescence. In: Howells JG (ed) Modern perspectives in adolescent psychiatry, vol 4. Brunner Mazel, New York, p 244

Received: 2 February 1981

Dr. R. B. Tattersall

Diabetic Department

Queen's Medical Centre

Nottingham University Hospital

Nottingham NG $72 \mathrm{UH}$, UK 